\title{
Integrated nutrient management to enhance biochemical resistance in rice against sheath blight
}

\section{Ramji Singh*, Durga Prasad and Alka singh}

Department of Plant Pathology, N.D. University of Agriculture and Technology Kumarganj, Faizabad (U.P.) INDIA. *Department of Plant Pathology,College of Agriculture,SVP University of Agriculture and Technology, Meerut (U.P.), INDIA

*Corresponding Author. E-mail: singh.ramji@gmail.com

Abstract: Application of potassium either as recommended, deficient or excess dose, enhanced the level of phenolic contents, increased incubation period and thereby decreased the sheath blight severity. Application of nitrogen and phosphorous, either as recommended, deficient or excess dose resulted in reduction of phenolic content, shorter incubation period and thereby increasing the sheath blight severity. Recommended sulphur application, enhanced the phenolic contents, increased incubation period and thereby decreased the sheath blight severity. Recommended zinc application resulted in enhancement of phenolic contents, longer incubation period and thereby decreasing the sheath blight severity. Excess application of zinc, reduced the phenolic contents and incubation period but the severity of sheath blight was also lowered down. Recommended iron application $(1.5 \mathrm{~kg}$./ha) enhanced the phenolic contents and incubation period with a decreased level of sheath blight severity. Deficient and excess doses of iron also showed the similar trend of effect on phenolics, incubation period and sheath blight severity.

Keywords: Rice, Sheath blight, Biochemical resistance, NPK, Micro nutrients, Integrated nutrient management, Phenolic contents

\section{INTRODUCTION}

Host resistance is an inherent and genetically governed trait of plants which help plants in fighting against all short of odds. Management of diseases through host resistance has become a prime concern of scientist and farmersboth. Using host resistance will not only minimize the ecological threats posed by fungitoxic chemicals applied for disease management rather it is cheaper also. Once a grower has opted for a resistant variety for cultivation then he need not to bother for application of any other control measures throughout the crop period. Application of fungi toxic chemicals also results in development of fungicidal resistance in many pathogens, hence sometimes it becomes very troublesome. Mechanism of resistance includes preexisting and post infectional structural and biochemical barriers. Biochemical defense is governed by many chemicals like common phenolics, phytoalexins, toxin detoxifying enzymes and enzyme inhibitors. Although these traits (Biochemical defens) are genetically governed but activity and level of some of these defense chemicals can also be manipulated by integrated application of macro and micro nutrients. Enhancement in nitrogen dose, interferes with plant metabolism in such a way that quantity of phenols get reduced, whereas with reduced or no application of nitrogen, quantity of phenols get increased, (Krauss, 2001) . In view of this, investigations were carried out continuously for two years i.e. during 2005 and 2006, to asses the effect of integrated nutrient application on induced host resistance and sheath blight development so that a holistic approach module can be developed for sustainable and eco-friendly management of this disease.

\section{MATERIALS AND METHODS}

Raising rice nursery: Healthy seeds of susceptible rice variety, Pusa Basmati-1 were soaked overnight in water and then surface sterilized with $2 \%$ sodium hypochloride solution for ten minutes and thereafter washed thrice with sterilized distilled water, dried in shade for $6 \mathrm{hrs}$. These seeds were sown using broadcast method in nursery on $7^{\text {th }}$ July in both the year i.e. 2005 and 2006. Fertilizers and other agronomic practices were followed as per recommendation for raising good and healthy nursery. Twenty five days old seedlings were transplanted in pots containing natural soil without any amendment and also soils amended with different doses of N, P, K, S, Zn and $\mathrm{Fe}($ Table-!). Three seedlings/hill were transplanted and each pot contained 3 hill. The transplanting was done on $1^{\text {st }}$ August in both the year i.e.2005 and 2006.

Since weight of soil in furrow slice in one hectare area is $2 \times 10^{6} \mathrm{~kg}$. and a healthy soil should contain an amount of 
N,P,K,S,Zn and Fe more than 250, 40, 250, 30, 2.4 and 16 $\mathrm{kg} / \mathrm{ha}$, respectively, hence prior to pot filling the soil analysis was done to determine the availability of these nutrients in soil and to decide the dose to be applied i.e. as deficient, as per recommendation and as excess in the pot containing $2.5 \mathrm{~kg}$ soil. The nutrients were supplied in the pot soil according to the doses given in table 1. Except nitrogen all the nutrients were provided as basal application, where as nitrogen was applied in split doses i.e. 50:25:25 ratio as basal dressing and top dressing as per recommendation. The experiments were conducted in completely randomized block design (CRD) with four replications of each treatments. interval upto 25 days of inoculation. Observations on sheath blight severity were recorded by measuring lesion length of individual plants inoculated along with plant height of respective plant. Relative lesion height (RLH) was calculated. (Meena etal.2001)

$$
\text { RLH }=\frac{\text { Lesion length }}{\text { Plant height }} \times 100
$$

Phenol estimation : The phenolic contents in rice plants were measured with the help of spectrophotometer following the principles and method given by Augustin, et al. (1985) Rice plant samples infected with $R$. solani were collected from the pots containing different levels

Table 1. Quantity (kg/ha) of nutrients present in soil $\left(\mathrm{T}_{1}\right)$ and applied in rice crop $\left(\mathrm{T}_{2}, \mathrm{~T}_{3}\right.$ and $\left.\mathrm{T}_{4}\right)$.

\begin{tabular}{|c|c|c|c|c|c|c|c|c|}
\hline \multirow{2}{*}{$\begin{array}{l}\text { Sl. } \\
\text { No. }\end{array}$} & \multirow{2}{*}{$\begin{array}{l}\text { Treat- } \\
\text { ments }\end{array}$} & \multirow{2}{*}{$\begin{array}{l}\text { Amounts of nutrients } \\
\text { available and } \\
\text { applied to the soil }\end{array}$} & \multicolumn{6}{|c|}{ Macro \& Micro nutrients* (kg/ha) } \\
\hline & & & $\mathbf{N}$ (Urea \& DAP) & $\mathbf{P}(\mathrm{DAP} \& \mathrm{SSP})$ & $\begin{array}{c}\mathbf{K} \\
(\mathrm{MOP})\end{array}$ & $\begin{array}{c}\mathbf{S} \\
\text { (Elementa } \\
\text { 1 sulphur) }\end{array}$ & $\begin{array}{c}\text { Zn } \\
\text { Zinc oxide) }\end{array}$ & $\begin{array}{c}\mathbf{F e} \\
\text { (Ferric oxide) }\end{array}$ \\
\hline 1 & $\mathrm{~T}_{1}$ & $\begin{array}{l}\text { (Control dose) naturally } \\
\text { available in soil (2005) }\end{array}$ & 118 & 9 & 156.80 & 13.12 & 0.724 & 13.89 \\
\hline 2 & $\mathrm{~T}_{1}$ & $\begin{array}{l}\text { (Control dose) naturally } \\
\text { available in soil (2006) }\end{array}$ & 120 & 9 & 156.50 & 13.28 & 0.712 & 13.72 \\
\hline 3 & $\mathrm{~T}_{2}$ & (Deficient dose) & 80 & 50 & 40.00 & 20.00 & 3.00 & 1.00 \\
\hline 4 & $\mathrm{~T}_{3}$ & (Recommended dose) & 120 & 75 & 60.00 & 30.00 & 5.00 & 1.50 \\
\hline 5 & $\mathrm{~T}_{4}$ & (Excess dose) & 160 & 100 & 80.00 & 40.00 & 7.00 & 2.00 \\
\hline
\end{tabular}

* Urea $(46 \%$ N),DAP(46\% P, $18 \%$ N),SSP (16\% P),MOP (60\% K),Elemental sulphur (100\% S),Zinc oxide (78\% Zn),Ferric oxide $(69 \% \mathrm{Fe})$

Inoculation of rice plants : The transplanted rice plants were inoculated at panicle initiation stage (crop growth stages 5) which comes after 60 days of seed sowing and remain up to 72 days of rice plants i.e. on $12^{\text {th }}$ September in both the year i.e.2005 and 2006. The inoculation was done by placing the ten-days-old, two to three mature sclerotium of $R$. solaniinside the sheath. The sclerotia were raised in petridishes containing PDA. For inoculation leaf sheaths were opened carefully and inoculum was placed with the help of sterilized forceps inside the sheath. Inoculated sheaths were wrapped with wet cotton pads so that moisture is retained after inoculation. A few drops of sterilized water were also added to inoculated sheath. Inoculation was done in the evening and inoculated plants were sprayed with water next morning. These plants were maintained in a net-house.

Appraisal of sheath blight development and severity : After inoculation, crop was regularly monitored for first appearance of disease symptoms. Disease severity were recorded, 7 days after inoculation and further at 5 days of N,P,K,S,Zn and Fe and were kept into a hot air oven at $55 \pm 5^{\circ} \mathrm{C}$ for $2 \mathrm{hrs}$ drying. Dried samples were cut into small pieces $(<1 \mathrm{~mm})$ which were mixed and kept into dessicator. Subsequently $1 \mathrm{~g}$ of the mixed plant sample was ground in a mortor with a pestle alongwith $20 \mathrm{ml}$ of $80 \%$ ethyl alcohol. After grinding of sample, mixture was filtered with the help of Whatman filter paper No. 1. One ml filtrate, $1 \mathrm{ml}$ phenol reagent and $2 \mathrm{ml}_{\text {of }} \mathrm{Na}_{2} \mathrm{CO}_{3}$ solution were taken together and volume was adjusted to $50 \mathrm{ml}$ by adding distilled water. Twenty $\mathrm{ml}$ of this preparation was kept in a test tube for $1 \mathrm{hr}$ and its optical density (O.D.) was recorded with the help of a spectrophotometer at $750 \mathrm{~nm}$ against blank reagent. Simultaneously a standard curve was prepared by using various concentration of gallic acid and concentrations of phenols were calculated in the test sample and expressed as phenol's weight in $\mathrm{mg}$ per $100 \mathrm{~g}$ dried plant material using following formula.

\footnotetext{
$\underset{(\mathrm{mg} / 100 \mathrm{~g} \text { dry wt. basis) }}{\text { Total phenol }}=\frac{\text { Amt. of gallic acid from std. } \mathrm{x} \text { Sample O.D. } \mathrm{x} \text { Volume made }}{\text { O.D. of known gallic acid } \mathrm{x} \text { Sample wt. } \mathrm{x} \text { Volume or aliquot }}$
} 


\section{RESULTS AND DISCUSSION}

Effect of Nitrogen: Findings of present investigations indicated that application of excess dose of nitrogen resulted in shorter length of incubation period and least quantity of phenols, with maximum disease severity as compared to recommended and deficient doses of nitrogen.(Table 2). Longer incubation period and comparatively higher quantity of phenols with least disease severity were recorded where no nitrogen was applied, followed by deficient or recommended nitrogen application. Kozaka (1961 and 1965) and Looetal. (1963) reported that the sheath blight was more severe on plants grown in soil with high nitrogen. Kozaka (1961) reported that the susceptibility of leaf sheath is closely correlated with its nitrogen contents, but not with its sugar or starch. Roy (1986) reported that sheath blight infection was maximum in rice plants grown with urea. Maximum infection occurred in plots which received urea in split doses. It seems that enhancement in nitrogen dose, interferes with plant metabolism in such a way that quantity of phenols get reduced. Whereas with reduced or no application of nitrogen, quantity of phenols get increased. During present investigation also excess dose of nitrogen enhanced the disease severity by decreasing the phenols. Thus, the findings of present investigation is quite in conformity with the reports of earlier workers like Kozaka (1961 and 1965), Loo etal. (1963), Roy (1986) and Krauss (2001). Higher dose of nitrogen promotes high vegetative growth and increase succulence in plants, thus, increases water content in the plant tissues which might have increased host proneness and susceptibility in the plants. These alterations might have resulted in shorter length of incubation period and increased severity of sheath blight. Hakulinen et al. (1995) also suggested that increased amount of phenols interferes with pathogenesis and ultimately results in lower severity of diseases.

Effect of Phosphorus: Application of excess dose of phosphorus resulted in shorter length of incubation period and least quantity of phenols, with maximum disease severity as compared to phosphorus application as per recommendation. Comparatively longer length of incubation period and higher quantity of phenols were recorded in treatments where additional phosphorus was not applied, followed by deficient or recommended phosphorus application. Least severity of sheath blight was also observed in the treatment where phosphorus was not applied, followed by deficient or recommended phosphorus application. Inoue and Uchino (1963) reported a higher disease incidence when a large amount of phosphate was added and a lower incidence when much potash was used. Roy (1986) reported that plants grown with crotonilidene diurea were less susceptible to the disease than those grown with guanylurea, phosphate and neem cake and castor cake coated urea. According to an Anonymous report (2007) plants use phosphorus for photosynthesis, respiration, storing carbohydrates, cell division, energy transport (ATP, ADP), nucleic acid, enzymes and phospholipids. Phosphorus plays a very central role in determining total energy of metabolism of the plant because it forms energy rich phosphate esters (C-P) such as glucose-6-phosphate. Excess phosphorus causes decrease in the uptake of zinc, iron and copper-which starts a chain reaction of other macro and micro nutrient deficiencies. Hence, deficient or excess phosphorus application affects the defense quality of plants against stresses. In both conditions the defense quality of plants reduced, while defense against stresses in plants determine by phenol compounds present in the cells and tissues; decreased phenols, decrease resistance in the plants. During present investigation also, excess dose of phosphorus enhanced the disease with reduced phenol contents. It is well supported by earlier reports of Inoue and Uchino (1963) and Annonymons (2007).

Effect of Potassium: Application of potassium in excess dose, resulted in comparatively longer length of incubation period, higher quantity of phenols with least disease severity. Comparatively shorter length of incubation period and lesser quantity of phenols were noticed when no potassium was applied, followed by deficient or recommended potash application. Maximum severity of sheath blight was also observed when potassium was not applied, followed by deficient or recommended potash application. Inoue and Uchino (1963) reported a lower disease incidence when a large amount of potassium was added and a higher incidence when much phosphate was used. Vijaya Bhaskar et al. (2001) reported that incidence of sheath rot of rice caused by Acrocylindrium oryzae decreased with increase in potassium level from 0 to 140 $\mathrm{kg} / \mathrm{ha}$. The phenol contents in leaf sheath increased with increase in potassium application. According to Krauss (2001), ratio between nitrogen and potassium plays obviously a particular role in pathogenesis. According to a literature reviewed by Perrenoud (1990) it is concluded that the use of potassium decreased the incidence of fungal diseases and increased the crop yields also. An inverse relationship between disease incidence and plant nutrition with potash in sheath blight has been coated by Haerdter(1997). Mondal et al. (2001) also found a negative correlation between potassium content in soybean and sesame with disease incidence and a positive correlation between their respective yield. According to Sweeneyet al (2000) the positive impact on yield could also be attributed to the effect of chloride supplied with $\mathrm{KCl}$ Fertilizer. During present investigation also excess dose, of potassium reduced the disease severity and increase the phenol contents which is supported by the findings of all workers cited earlier. 


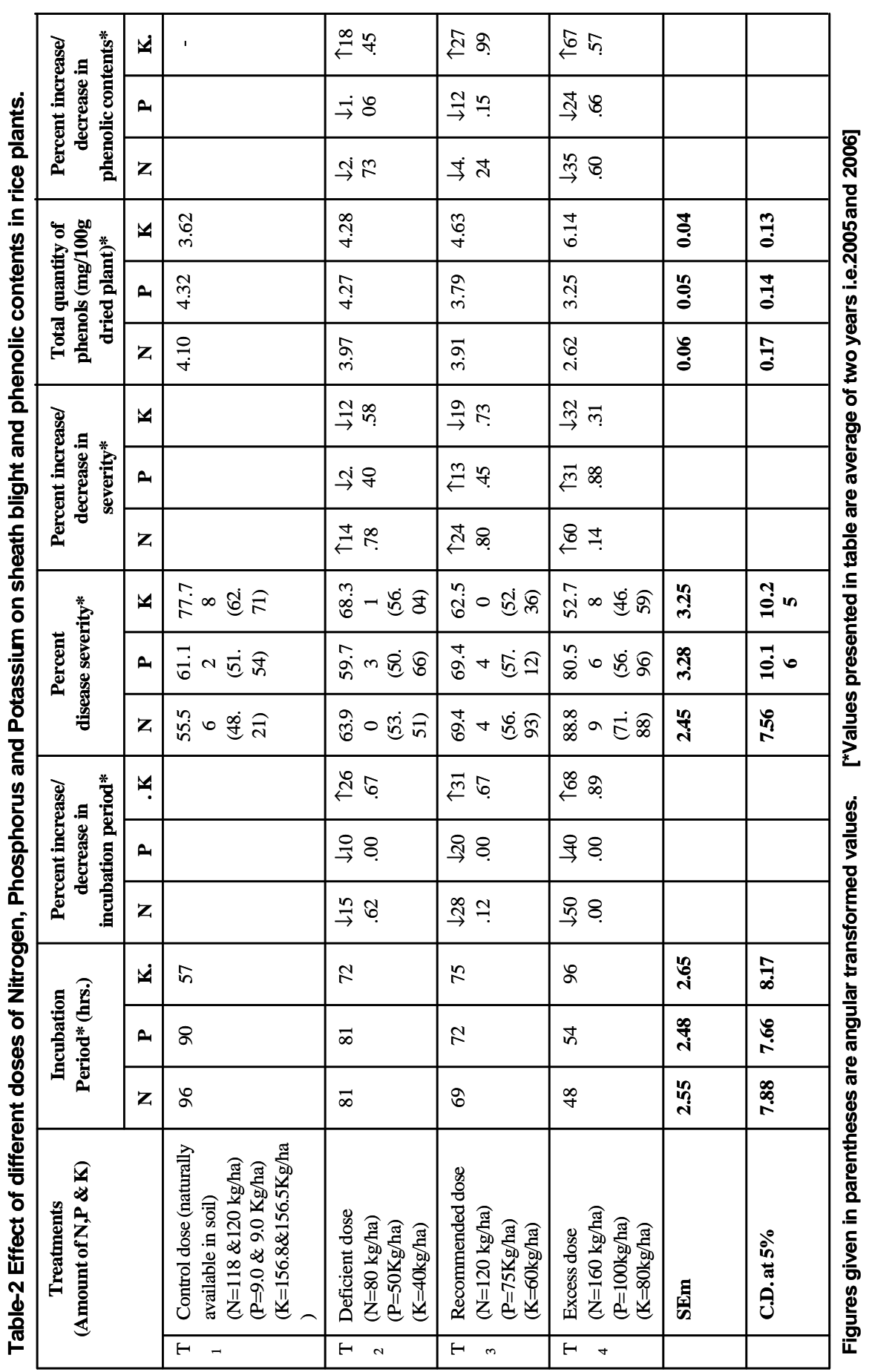




\begin{tabular}{|l|l|l|l|l|l|l|l|}
\hline \multicolumn{7}{|c|}{ Ramji Singh etal. /J.Appl.\& Nat. Sci. 1(1) 82-88(2009) } \\
\hline
\end{tabular}


Effect of Sulphur: Among the different doses of sulphur applied it was found that comparatively longer length of incubation period was recorded due to application of recommended dose of sulphur followed by deficient, excess and control (no application) dose application, respectively. Maximum severity of sheath blight was recorded when sulphur was not applied, followed by deficient or excess doses of sulphur application. Least severity of sheath blight was recorded due to sulphur application at recommended dose. Highest quantity of phenols was recorded due to sulphur application as per recommended dose followed by excess, deficient and control dose, respectively. Inoue and Uchino (1963), reported a lower disease incidence due to recommended micro-nutrients. Datre etal. (2003) reported that zinc sulphate check the growth of $R$. solani. Sulphur is a component of cystine and methionine (amino acids that make up plant proteins). Sulphur is therefore a component of plant proteins. Hence, imbalanced sulphur fertilization affects the phenol contents of plant, its deficiency reduce the phenols and its excessiveness also to be harmful for metabolic activities and therefore affects the defense mechanism with reduction in amount of phenols. The detailed role of phenols in biotic stress has already been discussed in earlier section on nitrogen. During present investigation also different doses of sulphur affects the phenols and disease severity. Thus the findings of earlier workers are quite supportive of present findings.

Effect of Zinc: Among the different doses of zinc, recommended dose of zinc application resulted in comparatively longer length of incubation period followed by deficient, excess and control dose (no application) of zinc, respectively. Maximum severity of sheath blight was observed in treatments where zinc was not applied, followed by excess or deficient zinc application, whereas least disease severity was recorded due to zinc application as per recommendation. In case of quantity of phenols, the highest quantity of phenols was obtained due to recommended dose of zinc followed by deficient, excess and control dose, respectively. Datre et al. (2003) reported that zinc sulphate check the growth of $R$. solaniin vitro. Kang (2000) reported the incidence of rice diseases due to zinc deficiency (4.4), iron deficiency (2.7), nitrogen deficiency $(0.8)$ and salt injury $(0.5)$. Inoue and Uchino (1963) observed lower sheath blight incidence with use of recommended dose of micro nutrients. Zinc is essential for growth regulation and also for regulating carbohydrate consumption. Zinc improves chlorophyll function. It is a component in many enzymes and is important in enzyme systems, particularly for water absorption and usage. During present investigation also imbalanced zinc application, affected phenols negatively and disease severity in a positive manner. However, recommended zinc application enhanced the phenols and reduced the disease severity. Thus, findings of earlier workers are quite supportive to present findings.

Effect of iron: Among the different doses of iron applied to the rice plants, the longest length of incubation period was recorded in the plants, applied with recommended dose of iron, followed by deficient, control (no application) and excess dose application, respectively. Highest severity of sheath blight was recorded in the plants where iron was not applied, followed by excess or deficient dose. Whereas the least disease severity was observed when iron was applied at recommended dose. The highest quantity of phenols was recorded due to application of iron as per recommended dose followed by deficient, excess and control dose of iron, respectively. Sarkar and Sinha (1991) found that ferric chloride gave protection to rice plants against sheath blight. Kang and Singh (2000) reported the incidence of rice disease due to zinc deficiency (4.4), iron deficiency (2.7), N. deficiency (0.8) and salt injury (0.5). Tiwari and Khare (2001) found that healthy seeds and seedlings of moong bean contained more phenols than the infected seeds and seedlings. The phenolic compounds inhibited the growth of $R$. solani. An adequate supply of soluble iron in the plant nutrient also inhibits the formation of phenol compounds (Annonymons, 2007). In present investigation also, excessive iron reduced the phenols in rice plants. Bodegom et al. (2005) reported that ferrous iron $\left(\mathrm{Fe}^{++}\right)$, which is abundant in waterlogged soils, significantly stimulates phenol oxidase activity, both in pure enzyme assays and in waterlogged soil slurries form nutrient-poor dune slacks. In present investigation it was observed that recommended iron application increased phenols and decreased disease severity, however excess iron decreased phenols and increased disease severity. Thus the present findings are on the similar line of earlier findings

\section{REFERENCES}

Anonymous (2007). Advanced nutrients. At info@advancednutrients.com (19.06.2007).

Bodegom, P.M.V., Broekman, R., Dijk, J.V., Bakker, C. and Rien, A. (2005). Ferrous iron stimulates phenol oxidase activity and organic matter decomposition in waterlogged wetlands. Earth and Environmental Science. 76 (1): 69-83.

Dantre, R.K., Rathi, Y.P.S. and Sinha, A.P. (2003). Elicitation of resistance in rice plants against sheath blight with nonconventional chemicals. Indian Phytopath., 3 :283-285.

Haerdter, R. (1997). Crop nutrition and plant health of rice based cropping system in Asia. Agro-Chemicals News in Brief, 20 (4): 29-39.

Hakulinen, J., Julkunen, R. and Jorma (1995). Does nitrogen fertilization have an impact on the trade of between willow growth and defensive secondary metabolism.Tree Structure and Function. 9(4): 235-240. 
Inoue, Y. and Uchino, K. (1963). Studies on sheath blight of rice plant caused by Pellicularia sasakii (Shirai) S. Ito. I. Ecology of damage and Chemical control. Ministry of Agriculture, Forestry and Fisheries Research Council, Japan Appointed Experiment No. 4 at Yamaguchi Agril. Experiment Station, $136 \mathrm{pp}$.

Kang, I.S. and Singh, D. (2000). Status of pathological and nutritional disorders or ice in Punjab. Pl. Dis. Res., 2 : 229231.

Kozaka, T. (1961). Ecological studies on sheath bligh of rice plant caused by Pellicularia sasakii (Shirai). S. Ito, and its chemical control. Chugoku Agril. Research., 20:1-33.

Kozaka, T. (1965). Ecology of Pellicularia sheath blight of rice plant and its chemical control.Ann. Phytopathol. Soc. Japan, $31: 171-185$.

Krauss, A. (2001). Potassium and biotic stress at www. ipi@ipitotash.org or www.ipiotash.org.

Loo, E.P., Choun, C.Q. and Lee, D.C. (1963). Studies on Rhizoctonia blight of rice. Acta Phytophylactica Sinica., 2: 431-440.

Meena, B., Ramamoorthy, V. and Muthusamy, M. (2001). Morphological and pathological variation in isolates of $R$. solani causing sheath blight of rice. Pl. Dis. Res. 16 (2) : 166172.
Mondal, S.S., Pramanik, C.K. and Das, J. (2001). Effect of nitrogen and potassium on oil yield, nutrient uptake and soil fertility in soybean (Glycine max) sesame (Sesamumindicum) intercropping system. Indian J. Agric. Sci. 71: 44-46.

Perrenoud, S. (1990). Potassium and plant health. IPI Research Topics No. 3, $2^{\text {nd }}$ rev. edition

Roy, A.K. (1986). Effect of slow-release nitrogenous fertilizers on the incidence of sheath blight and yield of $r$ Roy, A.K. (1986). Effect of slow-release nitrogenous fertilizers on the incidence of sheath blight and yield of rice.Oryza., 23: 198199

Sarkar, M.L. and Sinha, A.K. (1991). Control of sheath blight of rice by unconventional chemicals. Indian Phytopath. 3:379382

Sweeney, D.W., Granade, G.V., Eversmeyer, M.G. and Whitney, D.A. (2000). Phosphorus, potassium chloride and fungicide effects on wheat yield and leaf rust severity.J. Plant Nutr. 23: 9,1267-1281.

Tiwari, A. and Khare, M.N. (2001). Influence of plant age and phenolic contents of mungbean on resistance toRhizoctonia solani Kuhn. Indian Journal of Pulses Research., 14: 1, 67.

Vijaya Bhaskar, C. Rama Rao, G. and Reddy, K.B. (2001). Effect of nitrogen and potassium nutrition on sheath rot incidence and phenol content in rice (Oryza sativa L.). Indian J. Plant Physiol., 6: 254-257. 